\title{
O PATRIMÔNIO GASTRONÔMICO NA FRANÇA: COMO PENSAR UM MONUMENTO, DO ARTEFATO AO MENTEFATO?*
}

\author{
The Gastronomic Patrimony in France: \\ How to Think a Monument, from the \\ Artifact to the Mentifact? \\ Julia Csergo**
}

\begin{abstract}
RESUMO
A gastronomia ficou historicamente relacionada ao conceito de patrimônio na França. Esse fator se deve em parte ao lugar que lhe cabe na cultura francesa. O presente artigo pretende lançar algumas pistas de críticas aos conceitos de gastronomia e patrimônio que vêm alicerçando o conceito de patrimônio gustativo na França (a pesquisa completa será publicada em breve). Nesta direção, desprende-se o conceito de patrimônio do de monumento escrito e edificado, que historicamente tende a valorizar o universo material da elite, entendendo-o como a expressão representativa de pertencer a uma "cultura". O monumento, nesse contexto, é relacionado ao universo imaterial dos saberes, do savoir-faire, de práticas sociais e expressões populares que fundamentam a tradição gastronômica francesa.
\end{abstract}

Palavras-chave: patrimônio gastronômico; gastronomia francesa; patrimônio material e imaterial.

\begin{abstract}
* Tradução Giana Cristina Coró.

** Université Lyon 2. E-mail: julia.csergo@wanadoo.fr
\end{abstract}

Gastronomy in France was historically connected to the concept of heritage. This factor is partly due to the place that food occupies in French culture. This article raises some critical clues to the concepts of gastronomy and heritage that underpin the concept gastronomy heritage in France (a complete research will be published soon). In 
this direction, the concept of heritage is disconnected from the written and the built monument, which historically tend to emphasize the elite belongings, and passes to be understood as the representative expression of belonging to a "culture". The monument, in this context, is related to the intangible universe of knowledge, savoir-faire, social practices and popular expressions that underlie the French gastronomic tradition. Key-words: gastronomy heritage; French gastronomy; tangible and untangible heritage.

A gastronomia suscitou inúmeros estudos na área de ciências humanas. Entre estes, exceto a hipótese formulada por Pascal Ory, que enxerga nela uma racionalidade ${ }^{1}$, nenhuma definição científica lhe foi atribuída, especialmente pelos historiadores que se referem geralmente à abordagem feita por Brillat-Savarin (1755-1826). De maneira ainda mais problemática, a gastronomia é percebida como um monumento e como um patrimônio freqüentemente relacionado a um lugar, assim como um castelo ou uma catedral. De fato, a economia turística do início do século XX fez a gastronomia, pela relação intrínseca que ela estabelece entre consumo de espaço e consumo de alimentos ${ }^{2}$, ser assinalada em guias de viagens como "especialidades gastronômicas".

No decorrer dos anos, o trabalho acerca do conceito de patrimônio gastronômico ficou atrelado às análises dos conceitos de gastronomia e de patrimônio. Foram então delineadas, neste artigo, algumas pistas da pesquisa que será publicada em breve.

Do latim monumentum, aquele que recorda a memória de um homem ou de um evento, o conceito de monumento se construiu progressivamente, especialmente durante a década revolucionária, como um "testemunho que se impõe por sua massa" e que se refere tanto a um objeto transportável quanto a um edifício. No momento em que as primeiras instruções sobre inventário, conservação e preservação de certos monumentos "para a História" foram estabelecidas na Convenção, nasce a nova concepção do patrimônio coletivo de uma nação "completa e divisível", que levou, em 1975, à criação oficial do Museu dos Monumentos Franceses, e mais tarde, em 1810, à criação dos museus de província. mard, 1998.

1 PASCAL, Ory. Le discours gastronomique français des origines à nos jours. Paris: Galli-

2 CSERGO, Julia; LEMASSON, Jean-Pierre (Dir.). Voyages en gastronomie. L'invention des capitales et des régions gourmandes. Paris: Autrement, 2008. 
Ora, neste mesmo tempo, eruditos e escritores se reuniam para recolher, dentro da Academia Céltica (1805), dados nacionais até então negligenciados por culturas nobres e elitistas - tradições, costumes e línguas locais - em razão de seu interesse e antes de seu desaparecimento, supostamente próximo. O termo "monumento" está então no centro desta análise, como traço não somente material ou arquitetônico, mas, sobretudo, verbal, mental ou gestual da herança dos povos. Ora, estas enquetes, desacreditadas pela celtomania ultrajante de alguns e pelo desprezo então vinculado às culturas populares, foram retomadas por inúmeras sociedades doutas, constituindo um guia de referência para os trabalhos bem posteriores dos folcloristas (que encontrarão, por razões que não vem ao caso evocar aqui, pouco eco nas esferas acadêmicas).

A breve recordação deste quadro contextual freqüentemente negligenciado me parece indispensável à compreensão do processo de patrimonialização da gastronomia da forma como a pensamos hoje. Durante esta década revolucionária é que o discurso sobre a gastronomia como prática social e cultural da mesa nasce de fato, como se sabe, com Joseph Berchoux e principalmente com Grimod de La Reynière (1758-1837). Herdeiro de uma das maiores fortunas do Antigo Regime, Grimod "requalifica", pode-se dizer, a relação com a mesa das antigas elites pelos novos ricos do Diretório, do Consulado e do Império. Seu discurso inscreve inicialmente a gastronomia em uma herança elitista, em que a diversidade das produções alimentares da província encontra lugar. Diversidade que já conhecemos em parte, mas cuja magnitude se descobre graças à vasta pesquisa estatística das riquezas econômicas da França e de inventários arqueológicos, artísticos e históricos.

Em adequação, sem dúvida, ao advento do conceito de "monumento histórico" que marca sua época, Grimod evoca, na apresentação do Almanach des gourmands, de 1807, a primeira ideia de "monumentalização" da especialidade gastronômica como memória de um território, de seus homens e como "glória" nacional. Expressando esta convenção em um catálogo francês onde apareciam as "produções alimentícias que tornaram nossas cidades conhecidas", Grimod indica: "Assim, ao invés do campanário de Amiens, distinguir-se-ia em seu lugar o patê de pato; em Nérac, uma terrina de perdizes vermelhas; uma terrina de fígado de patos em Toulouse; pés e queijo de porco em Troyes; um pote de mostarda e um pote de épine-vinette (bérberis) em Dijon [...]". Esta cartografia foi realizada por Charles-Louis 
Cadet de Gassicourt em seu Cours gastronomique, publicado em 1809. Desde então, são os guias turísticos que assumiram o lugar desta cartografia e que instalaram, em nossas representações geográficas e históricas do território, o produto alimentar como monumento relacionado a um lugar.

O produto em si, monumentalizado em sua materialização, marcou durante muito tempo nossa concepção do que seria um patrimônio gastronômico. Como testemunha, tem-se o número de obras e de atlas gastronômicos franceses publicados ainda nos dias de hoje. No entanto, adotar apenas este ponto de vista significaria esquecer que, neste mesmo tempo em que o local media a relação da França com seu passado, os dados imateriais, que são o savoir-faire, as tradições e os costumes da mesa, fariam parte do repertório. Compilações de receitas e de obras eruditas enraízam a relação da mesa à sua qualidade, às suas tradições, aos seus valores humanistas e aos seus rituais em territórios e memórias, e isto muito além de segmentações geracionais, sociais, religiosas, econômicas ou políticas. Pode-se, sem dúvida, encontrar nestas abordagens uma filiação com a protoetnografia da França lançada no início do século XIX, assim como com os trabalhos dos folcloristas - como Paul Sébillot ou, posteriormente, Van Gennep - ou com os mantenedores do patrimônio etnológico, como George-Henri Rivière, fundador dos écomusées (expressão do tempo e do espaço que visa, antes de tudo, valorizar o patrimônio material e imaterial de um território ou de uma população). Além disso, não se deve admirar-se com o fato de que a reflexão sobre a gastronomia como "expressão cultural" que sintetiza as tradições populares e elitistas encontra-se mais em trabalhos de etnógrafos do que em trabalhos de historiadores. Isso se deve em parte às próprias fontes históricas que, sem dúvida, privilegiam o ponto de vista elitista, assim como aos trabalhos de história sobre as culturas populares, que integraram a alimentação apenas muito parcialmente. Apenas recentemente a alimentação passou a ser um objeto digno de pesquisa acadêmica.

O Inventário do Patrimônio Culinário da França, lançado em 1989 pelo Conselho Nacional das Artes Culinárias (CNAC - então dirigido pelo ministro da Cultura, Jack Lang, encarregado de elaborar e conduzir uma política cultural sobre o assunto), ilustra tanto a modelagem do processo de patrimonialização dos bens culturais "criados" durante a década revolucionária - repertório, institucionalização, transferência à soberania nacional, restituição - quanto a dualidade das abordagens - materiais e imateriais - que é vinculada 
ao patrimônio gastronômico. O Inventário se apresenta como um catálogo de produtos (patrimônio material) nascidos de saberes, de savoir-faire e gestos inscritos na memória de gerações e originários de uma tradição (patrimônio imaterial). Este trabalho representa um primeiro passo, essencial, para o reconhecimento dos produtos culinários como bem cultural e como patrimônio.

Apesar disso, a Convenção Unesco de 2003, relativa ao reconhecimento do patrimônio cultural imaterial da humanidade (lista de preservação ou proteção e lista representativa) e ao processo lançado pela França para a inscrição de um elemento de sua gastronomia, oferece-nos a possibilidade de um avanço que, provavelmente, nós não seríamos capazes de pensar e operar com os instrumentos nacionais que temos historicamente forjado em torno das concepções de patrimônio, e isto apesar do reconhecimento tardio, nos anos 1970, do patrimônio etnográfico que integra a imaterialização das tradições e dos costumes.

Se o produto cuja qualidade é resposta de sua tradição é, de fato, parte integrante da atenção que os franceses, particularmente, dão à mesa, pensar "também" a gastronomia como um patrimônio cultural imaterial levaria ao reconhecimento deste "monumento" não escrito e não edificado, que é a relação de uma sociedade toda ao comer e ao beber a uma gastronomia que seria a expressão representativa de pertencer a uma "cultura". Além disto, em um país que favoreceu o patrimônio material, nobre e elitista, repensar os patrimônios alimentares à luz da imaterialidade dos saberes, savoir-faire, práticas sociais e expressões populares, privilegiando o repertório e refazendo um inventário, abrir-nos-ia não apenas uma abordagem crítica da construção da noção de patrimônio gastronômico, mas ainda novas pistas de pesquisa em torno da unidade dos patrimônios.

Recebido em agosto de 2010. Aprovado em agosto de 2010. 